\title{
FACTOS DIVERSOS
}

Dr. Escorel-No dia 7 de Março, falleceu o Dr. Manoel Clementino de Oliveira Escorel, lente cathedratico da I. $^{\text {a }}$ cadeira de Direito Criminal.

Foi uma grande perda para a Faculdade de $\mathrm{Di}^{-}$ reito, pois o $\mathrm{Dr}$ Escorel, com a sua intelligencia lucida e os seus conhecimentos solidos, prendia sempre a attenção de seus alumnos, ministrando-lhes com facilidade as noções precisas para se encaminharem no estudo daquella sciencia, e se habilitarem á pratica da vida social.

O Dr. Escorel escreveu e publicou a obra " $\mathrm{Co}$ digo Penal Brasileiro», em dous volumes, muito apreciada pelos seus alumnos, e pelos que se dedicam a pratica criminal.

Dr. Vicente Mamede de Freitas-No dia 9 de Agosto falleceu repentinamente, n'esta Capital, o Dr. Vicente Mamede de Freitas, Director da Faculdade de Direito.

Lente cathedratico da cadeira de Direito Civil, o Dr. Vicente Mamede exerceu o magisterio por longos annos, sempre com a mesma severidade para comsigo e para com os alumnos.

Nomeado Director da Faculdade por Decreto de 7 de Dezembro de 1894, exerceu esse cargo até ao seu fallecimento. 
A Faculdade tomou o luto regulamentar, $\epsilon$ procurou honrar a sua memoria, além das demonstrações do momento, mandando fazer, a oleo, o retrato do finado para figurar na galeria da Faculdade.

\section{O novo Director}

Por Decreto de $\mathrm{I} 3$ de Agosto foi nomeado Director da Faculdade o Dr. Antonio Dino da Costa Bueno, lente cathedratico de Direito Civil.

O novo Director tomou posse do cargo a 2 de Setembro, e da solemnidade com que esse acto se realisou deu conta o "Estado de S. Paulo» na sua edicção do dia 4, e nos termos que seguem:

\section{Faculdade DE Direito}

Realisou hontem, ás I 2 horas e meia da tarde, a sessão de congregação da Faculdade de Direito, 'afim de dar posse ao director effectivo e ao cathedratico de Direito Civil, ultimamente nomeados.

$A^{*}$ sessão compareceram os lentes srs. drs. João Mendes Junior, Herculano de Freitas, Veiga Filho, Pedro Villaboim, Amancio de Carvalho, Candido Motta, Braz Arruda, Almeida Nogueira, José Ulpiano, Gabriel de Rezende, Reynaldo Porchat, Pinto Ferraz e Frederico Steidel.

Tomando a presidencia, o sr dr. Dino Bueno declarou aberta a sessão e expoz os fins para que foi a mesma convocada, depois do que convidou o $\mathrm{dr}$. João Mendes Junior, para assumir a presidencia.

Em seguida, o secretario da Faculdade, dr. Julio Maia, leu a nomeação official do dr. Dino Bueno para director da Faculdade. 
O dr. Braz Arruda requereu que fosse lançado na acta um voto de congratulações pela nomeação.

$\mathrm{O}$ dr. João Mendes Junior convidou então o dr Dino Bueno para tomar assento da cadeira de director.

Este agradeceu a distinç̧ão dos seus collegas, esperando que o corpo docente, bem como os estudantes, o auxiliem no desempenho do seu cargo.

O novo director declarou que a segunda parte da sessão era para dar posse ao lente de Direito Civil, dr. José Ulpiano Pinto de Souza, nomeado ca. thedratico de Direito Civil na vaga aberta pelo fallecimento do dr. Vicente Mamede de Freitas.

Após as formalidades do estylo, o dr. José U1piano prestou juramento e tomou posse da sua cadeira, recebendo os cumprimentos de todos os seus collegas da Congregação, presentes.

- Effectuou-se hontem, ás 8 horas da noite, na Faculdade de Direito, a sessão solenne em homenagem ao dr. Dino Bueno, em regosijo pela sua posse no cargo de director daquelle estabelecimento.

A commissão promovedora dos festejos fơi a residencia do dr. Dino Bueno, buscal-o em "landau», conduzindo-o até á Academia, onde os alumnos abriram alas á sua passagem, saudando-o com uma estrepitosa salva de palmas.

A fachada do edificio estava toda illuminada a gaz, vendo-se ao centro o distico "Salve, Dr. Dino". Desde a entrada do edificio até ao salão nobre onde se realisou a festa notavam-se tinas com flôres e palmas. O salão estava decorado com simplicidade e gosto.

No saguão do edificio, a banda de musica da força publica tocou varios trechos, entre os quaes o 
Hymno Nacional, á entrada e sahida do sr presidente do Estado e o Hymno Academico, ao começar e finalizar a festa.

A concorrencia foi numerosa e selecta, sendo todos os convidados recebidos á porta por uma commissâo composta dos seguintes academicos:

Maria Andréa de Oliveira, Maria Luiza de Oliveira, Eudoxia de Castro, Accacio Nogueira, Carolino da Motta e Silva, João Sampaio, João Luiz do Rego, Casper Libero, Manoel Elpidio Netto, Plinio Barroso, Alcibiades Delamare, Affonso Celso de Paula Lima, Carlos Bellegarde, Eurico Fonseca, Alexandre Macedo Soares, Joaquim Prates, Roberto Moreira, João Minervino, Erico Sodré e Braulio Mendonça.

Entre as pessoas presentes, que occupavam os principaes lugares no salâo, ao lado da Congregação podemos notar as seguintes:

Dr Albuquerque Lins, presidente do Estado, e seu ajudante de ordens capitão Carvalho Sobrinho; dr. Candido Rodrigues, secretario da agricultura e seu official de gabinete, sr. Antonio Felix de Araujo Cintra; commendador Mondin Pestana, tenente Marcilio Franco e Jorge Machado, representando respectivamente os srs. secretarios do interior, justiça e fazenda; dr. Correa Dias, presidente da camara municipal; Raymundo Duprat, prefeito interino, dr. João Passos, procurador geral do Estado; Jaques Dupas, consul francez; commendador Daniel de Abreu, consul do Paraguay e interino de Portugal; commendador André Sanchez Mosquera, vice-consul da Hespanha; senadores e deputados ao Congresso Estadual, membros do po. der judiciario, representantes dos gymnasios, Escola Normal, Escola de Pharmacia, Escola Polytechnica, Escola de Commercio, muitos academicos e grande numero de familias da nossa melhor sociedade. 
A sessão foi aberta pelo cathedratico de Direito Romano, dr. Reynaldo Porchat, que proferiu eloquentes palavras, referindo-se á cordialidade que sempre existiu na Academia entre lentes e alumnos.

Em seguida deu a palavra ao dr. Frederico Steidel, lente substituto de Direito Commercial, que leu o seguinte discurso:

A reiterada e amavel insistencia da commissão academica organisadora desta solennidade fez com que eu me animasse a usar da palavra, por parte do corpo docente da Faculdade, arrostando os receios de não poder corresponder á importancia da presente commemoração da data de hoje que ficará perpetuada nos annaes da nossa Academia.

Mas, srs., devo confessal-o francamente, mais, talvez, do que o vosso captivante convite, traz-me a esta tribuna um dever de gratidão pessoal, que me impunha, de preferencia a qualquer outro, a obrigação de vir saudar o nosso novo director, o exmo. sr. dr. Dino Bueno.

E', srs., que dentre os lentes desta Congregação eu sou o unico que fez parte da primeira turma de estudantes para a qual preleccionou o illustre mestre, que é hoje o director da Faculdade.

Era em I 883 , s. exca. tinha então sido nomeado lente substituto, após um brilhante concurso, e fora designado para reger a cadeira de direito natural, do primeiro anno.

Apesar dos longos 25 annos que são passados, apesar de todas as lutas e trabalhos, que representam esse largo lapso de cinco lustros, nunca se apagou do meu espirito a recordação das claras e attrahentes lições do mestre e, ainda hoje, é com um mixto de admiração, gratidão e saudarle, que eu volvo os olhos para esse trecho feliz da minha mocidade. 
Havia, pois, meus srs., essas duas razões, qual dellas mais imperativa, para que eu puzesse de lado os receios de não poder corresponder á vossa confiança e viesse saudar o mestre querido, com a conviç̧ão de que outros seriam por certo mais eloquentes e brilhantes, mas nenhum poderia ser mais verdadeiro e nem mais sincero, ao manifestar a alegria que todos nós sentimos vendo, na suprema direcção desta casa, o exmo. sr. dr. Dino Bueno.

Demais, senhores, a minha missão não offerece difficuldades invenciveis e, para desempenhal-a, bastará que eu deixe correr livremente do coração todos os sentimentos que neste instante o povoam e agitam, e por essa forma terei traduzido o pensamento de todos que abrilhantam com a sua presença esta festividade, e esses sentimentos são os de admiração, respeito e amizade em seguida virão as braçadas de flores coloridas e perfumadas, com que cobrirão $s$. exca. os oradores, que se seguem.

Admiração pelo brilhante talento do exmo. sr. director, a serviço de uma vasta e profunda cultura juridica, adquirida em continuo e consciencioso estudo da sciencia do direito.

Vós que o ouvis diariamente na sua cathedra de direito civil, que elle tanto eleva, sabeis quão clara, convincente e amena é a sua palavra, e conheceis tão bem como eu, que com tantos outros lentes da actual Congregação tivemos a honra de ser seus discipulos, os seus inestimaveis dotes de professor, claro na exposição, methodico ao desenvolver os assumptos; profundo nos conceitos que emitte e assiduo nos seus trabalhos.

A admiração que inspira a figura circumspecta do nosso director, estende-se fóra dos muros deste velho convento, e é o primeiro sentimento que se 
apodera de todos que delle se approximam, qualquer que seja a causa dessa approximação.

No dominio das letras juridicas, são notaveis os seus trabalhos, esparsos pelas paginas dos importantes processos de que tem tratado; pelos discursos doutrinarios na tribuna politica, e nos prelios que se travam aqui nas provas academicas.

No dominio da politica, que mais de uma vez o tem afastado temporariamente do magisterio, são relevantes os seus serviços prestados á patria, attestados pela culminancia das posições, em que tem sido collocado pela confiança de seus concidadãos, e das quaes, ao retirar-se, se vê rodeado dos applausos até dos adversarios.

A individualidade do exmo. sr. dr. Dino Bueno inspira-nos tambem um sentimento de sincero respeito, não só por ser a de um dos mais antigos professores desta casa, mais ainda pela experiencia, saber $e$ ponderação calma, de que se revestem as suas deliberações.

Eu tenho prazer, srs., em vos affirmar que ainda hoje sinto pelo nosso venerando director, actual, o mesmo respeito, que lhe tributava nos meus saudosos tempos de estudante, e maior é ainda o prazer de acreditar que todos vos alumnos desta Faculdade comparticipaes desse mesmo sentir.

Mas, srs., esse respeito do que eu acabo de falar, não é inspirado tanto pela autoridade dos cargos de que s. exa. tem sido investido em sua longa vida publica, e antes pela amizade, que sabe impor docemente aos que com elle convivem, tornando-os captivos de sua urbanidade delicada e da lhaneza do seu trato, concedendo favores sem os fazer valer e recusando o que é injusto sem magoar o postulante. 
Com todos esses predicados, que vós conheceis e que eu acabo de esboçar parcimoniosamente para não deslisar pelo terreno da lisonja, onde os elogios perdem o seu merito e podem ferir a modestia da pessoa elogiada, o exmo. sr dr. Dino Bueno é o verdadeiro homem para o cargo a que é chamado e a sua nomeação não podia deixar de provocar os applausos geraes, que levantou.

$\mathrm{O}$ ensino e o estudo das letras juridicas entre nós resentem-se indiscutivelmente de falhas, que se procuram remediar, por meio de reformas em elaboração.

Agora mesmo, no Congresso Juridico reunido no Rio de Janeiro, affirmou-se esse facto como uma verdade provada e procura-se estudar a sua causa. No Senado Brasileiro, a Commissão de instruç̧ão, examinando o projecto de reforma de ensino, vindo da Camara dos Deputados, manifesta-se na mais franca divergencia de idéas sobre este magno assumpto, que constitue uma das questões mais palpitantes da vida social de um povo, para cuja solução a cooperação dos competentes é um dever, que se impõe.

O trabalho dentro das Faculdades não é tão intenso, quanto seria para desejar, de modo que os professores, que querem ensinar e os alumnos que desejam aprender, nem sempre conseguem um resultado completo dos seus esforços.

A necessidade de melhoramentos materiaes na nossa installação escolar é conhecida de todos nós.

Para a solução de todos esses problemas e de tantos outros que surgem diariamente na vida de um grande estabelecimento de ensino, como é a nossa gloriosa Faculdade; para a conservação da indispensavel ordem e disciplina academica, a influencia do 
exmo. sr. dr. Dino Bueno, como direcıor, se fará sentir benefica e proficua, e podemos ter a certeza de que elle sempre se esforçará por manter e engrandecer a justa nomeada de que gosa a Faculdade de Direito de S. Paulo.

Eu acredito, srs., que interpreto com fidelidade o pensamento unanime da Congregação, neste dia, em que s. exa. asssume o exercicio do seu elevado cargo, assegurando que da parte de cada um dos professores desta casa, lhe será prestado o mais sincero apoio, e a mais espontanea cooperação, e de um e de outra é garantia segura a cordialidade dos sentimentos pessoaes de cada um de nós para com s. exa.

Antes de terminar permitti, srs., que aproveitando-me da confiança e da amizade que me demostrastes, convidando-me para falar aqui, em nome do corpo docente, eu vos dirija algumas palavras, directamente a vós, alumnos desta Faculdade.

E' preciso, srs., não vos esquecerdes de que da vossa cooperação depende em grande parte a maior facilidade, para que o venerando sr. director realise a sua missão em toda a sua plenitude.

E' mister que elle sempre encontre em vós o cumprimento incondicional do dever de apoiar, acatar e respeitar as suas resoluções; dever tanto mais facil de cumprir, quanto é certo que, pela confiança nelle depositada, tereis a conviç̧ão de que taes resoluções serão sempre justas e ditadas pela lei.

Deveis ter sempre presente no vosso espirito, que algumas vezes o ardor dos vossos impulsos juvenis precisará ser attenuado pela calma e ponderação da experiencia dos homens e clas coisas, o que só se adquire com o perpassar dos annos e o decorrer da vida. 
E' essencial que vos recordeis que o vosso primeiro dever, e a unica fórma de vos elevardes moralmente aos vossos proprios olhos, é respeitardes o vosso director, pois não ignoraes, desde que penetrastes pela primeira vez nesta casa, que o que mais nobilita o homem como um ser livre e racional é o cumprimento espontaneo do seu dever.

Aliás, de que é esse o vosso modo de ver, demonstra-o a presente festa, organisada com tanta pompa pela vossa nobre iniciativa, e que pela sua espontaneidade é da mais alta significação moral.

A ella concorre pressurosa a Congregação dos lentes desta Faculdade, e comparticipando do enthusiasmo dos seus distinctos alumnos, vem, com toda abundancia de coração, manifestar publicamente ao exmo. sr. dr Dino Bueno os seus protestos de respeitosa estima, os seus applausos ao acto do Governo Federal, escolhendo-o para o cargo, em que foi hoje empossado, e os votos sinceros que faz para que a sua administração seja prolongada e feliz, e que ao terminal-a, s. exa. possa mais uma vez en sua vida proferir a phrase mais eloquente que é dada ao homem publico pronunciar, dizendo: Cumpri o meu dever.

Teve depois a palavra o bacharelando Lino Moreira, que proferiu o seguinte discurso, em nome dos alumnos da Faculdade:

"Exmo. sr. dr. Dino Bueno.-A' nobre commissão promotora desta solennidade roguei, implorante, que outro nome mais digno vos dirigisse a palavra de jubilosa saudação, ao tomardes posse do altissimo cargo de director da Faculdade de Direito de São Paulo.

A vossa personalidade é muito illustre para que pudesse eu, com fulgor, transmittir-vos o alvorotado 


\section{- I69-}

enthusiasmo que tomou o espirito de todos nós ao vos sabermos nomeado director

Foi, de facto, um rumoroso triumpho para esta gloriosissima Casa ter-vos ella arrancado ás seducções embriagantes mas perficlas e fallazes dessa hediondez sem entranhas - a Politica tentaculisante, diabolica e cruel.

Já era uma victoria

Maior porém é a que obtemos tendo-vos definitivamente ligado á suprema superintendencia academica, a vos, sr. dr. Dino Bueno, cuja solida e brilhante cultura juridica, cuja capacidade excepcional de professor e, em destaque, com o vosso aprimorado trato gentil e fidalgo para com todos, garantis soberbamente, a esta mocidade altiva, uma direcção dignificadora e memoravel.

Quando "leader» do governo num periodo tempestuoso da nossa historia politica, a par dum espirito vigoroso de discutidor sereno e calmo, dum cerebro magnificamente apparelhado dos recursos inexgottaveis duma infallivel sabedoria, revelaveis tambem uma sensatez, uma tão irresistivel cordura, tão fortes tendencias conciliadoras que o vosso nome, entre tantos egregios, era um dos de mais envolvente encanto e fascinação

Melhor que nós, sabeis e tendes o vivissimo sentimento de responsabilidade enorme que anda substancialmente acorrentada á direcção deste afamado Curso de Direito. Da elevação clara e descortinadora de vistas de quem a exerce dependem, não ha negar, o aprumo e a nobreza tradicionaes que o amor ao trabalho e aos ideaes creou para esta Faculdade.

A superioridade de espirito e cultura do director reflecte-se imperceptivel mas efficaz sobre todos os 
grandes como pequenos movimentos da vida academica

E que jámais falte vindo até nós, os moços, ás vezes vulcanisados pela divina loucura do Ideal ou impetuosos, a palavra sensata, paternal e amiga, feita de experiencia e de bondade

Nós, porém, orgulhosamente, em vós confiamos.

Mas se hesitasseis, tinheis a vos inspirar as sombras sagradas do venerando Ramalho, a austeridade honesta de Vicente Mamede e a figura esculptural desse que a gloria denominou-João Monteiro

Em nome dos meus collegas e no do Centro Academico "Onze de Agosto", eu vos felicito e saudo»!

Em nome do terceiro anno falou depois o academico Alfredo de Assis, que disse as seguintes palavras:

Henrique IV, aquelle romatico e valoroso principe de Navarra, a quem uma audaciosa campanha abriu as portas de Pariz, presidindo em I596, aos estados geraes, começou a fala do throno com estas palavras: "Se eu tivesse a pretenção inutil de passar por um bom orador, traria para aqui, mais phrases bonitas de que boa vontade, mas a minha ambição visa um fim mais elevado do que falar bem, aspiro ao glorioso titulo de libertador e restaurador da França».

Eu tambem, ao subir a esta tribuna, tantas vezes glorificada, de onde talvez falasse Castro Alves e donde falou Joaquim Nabuco, trazido pela bondade dos meus amigos e pela sympathia dos meus collegas, venho guiado, não pelo desejo inconfessavel desse ephemero triumpho, ao colher as palmas, que a vossa generosidade não me negará por certo, mas impellido 
pela ambição elevada de cumprir um dever gratissimo, qual o de trazer as saudações sinceras do terceiro anno, ao preclaro mestre, que entra a presidir os altos destinos desta Faculdade de Direito de S. Paulo.

Eu ambiciono apenas que a rudeza, quasi selvagem, da minha palavra possa reflectir a satisfacção, que enche o coração dos moços academicos, vendo ascender á direç̧ão desta Academia o mestre que ha tanto tempo, pelos seus altos dotes de espirito, tem sabido sustentar sempre as velhas prerogativas desta casa.

Ao ficar o supremo posto deste Cenaculo Juridico nas mãos do notavel jurista, o dr. Dino Bueno, que nesta solennidade assume a jurisdicção do seu cargo, não se interrompem as sacratissimas tradições desta Faculdade; o notavel professor de Direito Civil recebe uma injuncção perfeitamente digna da sua alta capacidade e o applauso unanime, que o acolhe no liminar da sua administração, é o registador sensibilissimo de quanto foi justa a sua escolha para dirigir a primeira Academia do Brasil; esta donde têm partido os melhores cidadãos do paiz, esta para onde sempre se têm voltado os olhos anciados da patria, nos momentos supremos e decisivos das grandes crises sociaes.

Os velhos navegadores normandos, cuja coragem se testemunha pela phrase orgulhosa de Badur, rei de Upsal, afrontando os temporaes e dizendo, em zombaria aos deuses: "eu só confio nas minhas forças», no declinio ultimo da sua vida aventurosa acostumavam a queimar o quanto possuiam, para que os filhos se entregassem ás azas das tempestades em busca de outras riquezas.

Nós rompemos esses costumes, que rasgavam as tradições e faziam desapparecer, para todo o 
sempre, o nome dos que se iam, e obrigavam aos novos, á luta insensata do eterno iniciamento.

Nós amamos conservar as velhas sombras do Passado, reliquias venerandas de outros tempos. E' assim, que ahi estão, na pompa das suas molduras, os retratos dos antigos Mestres desta Academia, que, partindo para a "impenetrabilidade do Não-Ser", aqui deixaram indissoluvel saudade dos seus nomes, os nomes inesqueciveis das suas victorias e as victorias memoraveis que glorificaram. E é justo evocal-os hoje, em que esta casa se veste de galas.

Cultores magnificos da sciencia complexa, de que somos os menores iniciados, deixaram, nas paginas das suas obras, o irrecusavel documento da sua gloria, cuja repercussão vibrante se irá eternamente multiplicando, em ondas sonoras, através da caligem dos tempos e através dos nevoeiros dos seculos. Desappareceram ao nosso campo visual, nunca desapparecerão á nossa saudade e á nossa admiração. Como que ainda vive aqui a figura severa do ultimo director, tanto se affeiçoara a vel-o, tanto se identificára nesta Academia, nos largos annos em que o venerando mestre, aqui gastou as energias vivas da sua intelli. gencia e as luzes raras dos seus conhecimentos.

Antes delle já daqui se fôra o dr João Monteiro, o mestre prezadissimo, o sabio, cuja poderosa mentalidade, cuja erudição quasi incalculavel, não poderam condensar-se nesses seus admiraveis livros, joias buriladas e ricas da nossa literatura juridica.

Athleta formidavel do estudo, pontifice calmo e correcto do Direito, investigador magnifico dos complexos phenomenos juridico-sociaes, ahi ficaram os seus variados trabalhos, no fôro, na cathedra $e$ na tribuna, attestando o seu valor, testemunhando o seu genio e onde a admiração se divide, ora para atten- 
der á profundidade do conceito, ora para attender á louçania do estylo suave e attrahente, que ensina e deleita, que seduz e preceitua, pondo na obsoluta aridez de uma questão difficil o espanejamento de ouro da poesia.

E já mais tarde, o vulto mais querido talvez, de quantos esta Academia venera, o veneravel sr. barão de Ramalho, que, por tantos annos illuminou esta Faculdade com o clarão magnifico do seu talento. Mas deste só cabe repetir a phrase, rapida e precisa, curta e justa, com que Ben-Janson se referia ao maior poeta da Inglaterra: "oh! não façamos intervir a divindade»! E Ramalho é para nós um idolo, uma divindade familiar, que occupa o preciptio lugar entre os pennates, cujo raro espirito paira sobre nosso estandarte, impellindo o para as elegrias viris dos combates e para o prazer violento das victorias.

Mas eu não quero, senhores, tentar o estolido arrojo de analysar-lhes as obras valorosas, nem moldurar, na aspereza da minha palavra, o clarão vivo dessas constellações, que se obumbraram na penumbra da Morte! Memorias eternas! Mestres inesqueciveis! $\mathrm{Eu}$ quiz apenas, evocando a magnitude dos seus nomes envoltos, como as cabeças esculpturaes das santas, no halo santissimo da saudade dos moços academicos, poder saudar, no illustrado jurisconsulto, que é hoje elevado á directoria deste estabelecimento, o conti. nuador glorioso dessa extraordinaria dynastia de sabios!

Quero saudar no novo director desta Faculdade, o depositario digno dessa herança gloriosa, legado preciosissimo de 80 gerações, que por aqui passaram!

Esses que foram, continuam, entanto, animando os novos, estimulando os que trabalham, como a figura pallida de Cid, que após a morte, pela astucia industriosa de um dos seus soldados, ia conduzindo através 


\section{- I $74-$}

dos combates gloriosos, as suas hostes aguerridas levando-as á volupia do triumpho, na embriaguez das musicas guerreiras, tecendo-lhes as corôas impereciveis das suas victorias.

E nesta evocação justissima, mostramos, que a mocidade não esquece nunca os grandes triumphadores, reverencia sempre, com as palmas espontaneas da sua admiração, com o enthusiasmo estridente dos seus applausos, esses que seu labor incessante, souberam conquistar o culto da Patria e as bençams dos povos.

E quando elles se vão "pelo caminho dos cysnes», como diziam as sagas da Noruega, perduram ainda, pelo exemplo, como estatuas impalpaveis, como genios familiares, evocados em todas as tristezas, celebrados em todas as festas, saudades através de todos os tempos e através de todas as edades.

Mas se estes, como na phrase vaidosa de Cervantes, "prenderam a penna muito alto", nem por isso deixou de haver quem a tomasse, pois, o egregio mestre, que hoje assume a direção desta Faculdade, é competentissimo para tiral-a ás suas mãos fidalgas, e em qualquer altura em que ella estivesse. Ha vinte annos, ha mais talvez, que as gerações que aqui se succedem, levam a todos os recantos do paiz, os profundos conceptos de seu ensino seguro, hoje sóbe s. exa. á suprema dignidade deste estabelecimento, e mestres, e discipulos, confraterisados, num só impulso, apresentam-lhe as homenagens a que tem direito, confundindo-se nesta admiravel harmonia, as saudações melhores dos seus companheiros, o respeito mais decidido e a admiração mais verdadeira dos seus alumnos, certos todos que nunca serão desmenticlas as velhas tradições desta casa.

Já trouxeram outros aqui, no crystal facetado e limpido das suas phrases a interpretação perfeita das 
saudações da Faculdade ao dr. Dino Bueno. Com o estarem as nossas, envolvidas, na trama pobre de phrases mais simples, não o são, emtanto, menos sinceras. Veja apenas o mestre insigne, nestas palavras a verdedeira estima e à mais alta consideração em que o têm os seus alumnos do terceiro anno, que o saudam, e a admiração forte que tributam ao seu brilhante passado, todos esses largos annos, em que tem preleccionado, uma das mais difficeis categorias do direito nas illuminadas cathedras desta Faculdade.

Mas não se trata, senhores, como dizia o glorioso Tobias Barreto, numa saudação eloquente ao mestre paulista: não se trata de repetir pela millesima vez um hymno ao merito do mestre, insistir sobre esse assumpto, variar sobre esse thema, com o concurso mesmo de novas flores e de novas palmas. E' uma especie de pleonasmo esthetico.

Ainda que tivesse as melhores idéas a oppôr ao frenesi provocado pela sua presença, seria, de certo, acto de desaso querer temperar o vinho, que transborda da taça dos outros, com a agua da minha taça». Sim, meus senhores, eu tambem não desejo misturar a agua da minha taça ao vinho que transborda a dos outros. Cumpro portanto, o mandato, que meus collegas me impuzeram, a mim, o menos competente talvez para isso, e trago ao exmo. dr Dino Bueno, as felicitações sinceras $\epsilon$ as flores que the offerecem os seus discipulos, pelo alto encargo, que o governo da Republica, tão merecidamente, the confiou.

E é apenas, esperar justamente o que s. exa. fará, saudar no dia de hoje o prologo de ouro de uma administração, que honrará sempre esta Faculdade de Direito de S. Paulo, que como a antiga Roma, essa Roma que sonho ás vezes, cheia de gladiadores e de reis, cheia de purpuras e de miserias, cheia de 
jardins e de aqueductos, cheia de ruinas patricias e tumulos abertos, guarda em cada pedra uma tradição de gloria e esconde em cada sombra uma reminiscencia feliz.

E cumprimentando ao novo director temos a convicção forte, de que se poderá dizer de sua exa. a phrase com que Sparta, na severidade escrupulosa dos seus principios, premiou o feito de Leonidas: «cumpriu o seu dever» $E$ isto porque, pela asseveração documental do seu alto valor, é sabido que sua exa. merecerá sempre, como tem sempre merecido, essa affirmação, que na sua incișiva justiça, é o unico monumento que póde premiar a memoria de um nome, a grandeza de um feito e o triumpho de um forte!

Associando-se á justa homenagem que os academicos de direito prestavam ao seu novo director, falou, em nome dos alumnos da Escola de Commercio Alvares Penteado, o sr. Mario Alvares de Abreu, que proferiu a saudação seguinte:

"Exmo. sr. dr. Dino Bueno, douta congregação, minhas senhoras, meus senhores.-Ao encetardes hoje, os trabalhos, como director da Faculdade de Direito de S. Paulo, nós, os alumnos da Escola de Commercio Alvares Penteado, que represento, não podiamos deixar de participar desta extraordinaria festa, com que a digna classe academica de S. Paulo celebra tão solenne acto.

A influencia incomparavel, o prestigio immorredouro que esta velha e gloriosa Faculdade exerce sobre a mocidade estudiosa do paiz inteiro, põe-na em destaque tão brilhante que a Escola de Commercio entende dever tomar parte nesta solennidade pela qual se festeja o inicio dos trabalhos de v. exa. nesta casa.

A harmonia existente entre as duas escolas, o grandioso fim que ambas têm, o engrandecimento da 
patria, fazem com que a nossa attenção hoje se volte inteiramente para v. exa., não só pelas eminentes qua lidades de v. exa., mas tambem por uma razão de ordem mais geral de que: se um novo "um novo" director toma posse da gloriosa casa, isso significa que ella continúa a exercer, entre nós, a nobilissima missão de divulgar sãos principios, aqui ministrados.

Essa festa nos é, sobremodo, sympathica, tão sympathica quanto significativa, porquanto nesse momento, se nos apresenta a feliz. opportunidade de congratularmos con a Faculdade de Direito pela escolha do nome de $\mathrm{v}$ exa, para o alto cargo que hoje assumis.

Não podia haver momento mais propricio para esta congratulação, tanto mais que falamos ao mais alto membro" da douta congregação.

Em signal, pois, do nosso regosijo-e fazendo votos pela feliz administração de v exa., nesse hon. roso cargo-juntamos applausos e applausos sinceros aos da mocidade academica que ora recebe $v$. exa. como amigo, mestre e director.

Estas flôres significam as nossas homenagens»

Em seguida o sr. Mario Alvares de Abreu e o sr. Mendes Peake, que representavam os alumnos da Escola de Commercio naquella festa, cumprimentaram o dr. Dino Bueno.

O dr. Dino Bueno, finalmente, agradeceu em longo e brilhante discurso, a prova de apreço de que era alvo, recordando que se achava cercado do que em $S$. Paulo ha de mais selecto na politica, nas sciencias, na literatura e na arte. A todos, commovido, agradecia, e em especial aos seus collegas da congregação e aos seus alumnos, de cuja bôa vontade e efficaz solidariedade, dependia o exito da sua missão. 


\section{$-\mathrm{r} 78-$}

E terminou, após referencias ao papel que, graças ao ensino do direito, o Brasil conquistou no conceito das nações, exhortando os academicos a que o auxiliassem no cumprimento arduo da missão que lhe foi confiada.

A sessão foi abrilhantada por uma orchestra que executou os seguintes trechos de musica, sob a direcção do professor Saverio Nigro:

Hymno Academico-Symphonia do "Guarany" - «Minuette»-de Bocherini-Fantasia da "Geisha» -Ouverture da opera "Martha», de Flotow.

A sessã̃o terminou ás io horas da noite, sendo o dr. Dino Bueno, ao retirar.se, acclamado pelos estudantes, que abriram novamente alas á sua passagem. 